\title{
Serum Homocysteine and Behavioral and Psychological Symptoms of Dementia: Is There Any Correlation in Alzheimer's Disease?
}

\author{
Ravi M. Soni ${ }^{a}$ Sarvada C. Tiwari ${ }^{a}$ Abbas A. Mahdi ${ }^{b}$ Neera Kohli ${ }^{c}$ \\ ${ }^{a}$ Department of Geriatric Mnetal Health, King George's Medical University, Lucknow, India; b Department of \\ Bichemistry, King George's Medical University, Lucknow, India; 'Department of Radiodiagnosis, King George's \\ Medical University, Lucknow, India
}

\section{Keywords}

Cognitive dysfunction - Dementia - Vitamin B12 .

Hyperhomocysteinemia

\begin{abstract}
Background: There are studies showing the relation between serum B12, folate and Behavioral and Psychological symptoms of Dementia (BPSD) in Alzheimer's disease (AD). Serum levels of these vitamins do not reflect actual disease status and therefore checking the serum Homocysteine level is considered a better test. Homocysteine has been found to be associated with cognitive impairment and various psychiatric disorders. Purpose: This study was planned to identify the correlation between serum homocysteine levels and BPSD in AD patients. Methods: AD patients $(n=18)$ and healthy controls $(n=18)$ were included in the study. Diagnosis of AD was confirmed using International Classification Disease-10. AD patients were assessed using Mini Mental Status Examination (MMSE), Clinical Dementia Rating scale (CDR), Global Deterioration scale (GDS), and Neuropsychiat-
\end{abstract}

ric inventory (NPI). Healthy controls were assessed on MMSE and Mini International Neuropsychiatric Interview. Serum homocysteine, vitamin B12, and folate levels were measured in all study subjects. Results: Patients with AD had statistically significant higher serum levels of homocysteine as compared to the control group, while the levels of vitamin B12 and folate did not differ significantly. There was statistically significant positive correlation of serum homocysteine levels with total NPI score as well as with NPI sub-domains particularly delusion, agitation/aggression, and depression/ dysphoria. Serum homocysteine levels did not correlate significantly with MMSE, CDR, and GDS scores. Conclusion: Correlation was observed between serum homocysteine levels and behavioral and psychological symptoms of AD. There is a possibility of etiological role, but the underlying pathophysiological mechanisms need to be elucidated. Whether patients will benefit or not with supplements of vitamin B12 and folate requires further research. This was a cross-sectional study and findings should not be generalized. Further prospective longitudinal studies with a large number of patients are needed.

\section{KARGER}

(C) 2018 S.Karger AG, Basel

E-Mail karger@karger.com

www.karger.com/aon
Dr. Ravi M. Soni

Department of Geriatric Mental Health, DM Senior Resident

King George's Medical University

Lucknow 226003, Uttar Pradesh (India)

E-Mail ravi.psychiatrist@gmail.com 


\section{Introduction}

Alzheimer's disease $(\mathrm{AD})$ is characterized by the progressive loss of memory and learning processes, visuospatial abnormalities, confusion, and disorientation $[1,2]$. Though, $\mathrm{AD}$ is associated with cognitive dysfunction with usual initial clinical presentation with memory complaints, it is prudent to identify the behavioral and psychological symptoms of dementia (BPSD), which can be present even in the mild form of the AD. BPSD consists of abnormalities of thought, perception, mood, and behavior in dementia patients $[3,4]$, which were suggested as core symptoms of dementia along with cognitive symptoms by Tariot et al. [5].

Studies suggest that 70-90\% of AD patients may experience delusions, hallucinations, depression, agitation, and other BPSD [6, 7]. BPSD is the most challenging aspect of the disease, which increases the burden for the caregiver and it is also the cause of repeated hospitalization and deterioration in the quality of life in $\mathrm{AD}$ patients as compared to those with only cognitive symptoms [8].

Because the treatment of dementia is very difficult, the emphasis is on the early identification and management of BPSD. By doing this, one can improve the quality of life of patients with dementia and reduce the burden on the family for caring them.

It has been found that the concentrations of serum B12 and folate are low $[9,10]$ and some psychiatric disorders are present in in $\mathrm{AD}$ patients [11], but significant correlation was not found between serum vitamin B12, folate levels and BPSD in previous studies [12, 13]. However, few studies have assessed the correlation between BPSD of dementia patients and the plasma total homocysteine (tHcy) concentration [14], but results are not consistent. In addition to this, serum vitamin B12 and folate levels may not reflect the actual status of these vitamins in brain as well as the current disease status. Therefore, the homocysteine levels are considered a better test than serum vitamin B12 and folate measurement [15].

Homocysteine is an important amino acid, which is produced during the metabolism of methionine. If homocysteine is not converted to methionine or cysteine, it gets accumulated and can act as a neurotoxin by causing calcium influx through N-Methyl D-Aspartic acid receptor channels or by increased generation of free radicals. Because the enzymes necessary for metabolism of homocysteine or its conversion to cysteine or methionine require folate and vitamin B12, the deficiency of folate and vitamin $\mathrm{B} 12$ can result in increased blood homocysteine levels [14]. When homocysteine gets accumulated, it in- hibits the production of prostacyclin, which is involved in thrombus formation and blood pressure control and leads to the accumulation of low-density lipoprotein, which damages the blood vessel wall. Finally, homocysteine damages the blood vessel and causes blood clotting or thrombus formation and acts as a strong toxic substance in the body, which is implicated in the pathogenesis of cardiovascular and cerebrovascular disorders like arteriosclerosis, dementia, and stroke $[16,17]$.

Studies have shown that increased blood homocysteine levels are not only correlated with cardiovascular diseases but also with the severity of cognitive damage and dementia. Moreover, it has been found that hyperhomocysteinemia is correlated with psychosis, depression, and other psychiatric disorders $[18,19]$. Elevated blood homocysteine level has shown to be related to pathophysiology of psychosis in young male patients with schizophrenia [14]. Studies have also shown correlation between hyperhomocysteinemia and cognitive dysfunction in patients with bipolar disorder $[20,21]$ and schizophrenia [22]. One study found that low folic acid and high homocysteine, but not low vitamin B12 levels, are correlates of depressive symptoms in community-dwelling middle-aged individuals [23]. Another study by Almeida et al. [24] showed that that older adults with high tHcy had increased risk of depression. From available literature, it has been presumed that BPSD may be correlated with plasma homocysteine levels in $\mathrm{AD}$ patients. It is hypothesized that "elevated total plasma homocysteine levels correlated with BPSD and its sub-domains in AD patients".

There are very few studies that have assessed the correlation between serum homocysteine level and BPSD. The existing research is limited and only 3 studies with similar hypothesis were found. All of these studies have shown conflicting results [25-27]. So, on the basis of previous results suggesting that plasma homocysteine levels are associated with risk and symptoms of $\mathrm{AD}$, the plasma homocysteine levels and BPSD in Indian AD patients were assessed and investigated to find any correlation between them. Research studies on the role of homocysteine in BPSD of AD patients from India are not available.

This study was aimed to find any correlation between homocysteine and BPSD and its sub-domains in Indian $\mathrm{AD}$ patients.

\section{Methods}

Participants

The sample consisted of 36 participants: $18 \mathrm{AD}$ patients and 18 healthy controls. Between January 2015 and December 2015, all AD patients were recruited from outpatients and inpatients of the de- 
Table 1. Demographic, clinical, and biochemical characteristics of AD patients and controls

\begin{tabular}{lccrc}
\hline & Control $(n=18)$ & AD $(n=18)$ & $\mathrm{U}$ & $p$ value \\
\hline Age, years & $70.94(7.4)$ & $74.5(8.54)$ & 123.00 & 0.222 \\
Gender, male:female & $10: 8$ & $10: 8$ & & \\
Education, years & $5.16(4.95)$ & $5.67(5.85)$ & 155.00 & 0.827 \\
MMSE & $23.89(2.68)$ & $14.44(4.15)$ & 13.50 & $0.000^{\dagger}$ \\
Homocysteine, $\mu \mathrm{mol} / \mathrm{L}$ & $11.59(1.51)$ & $19.11(5.45)$ & 16.00 & $0.000^{\dagger}$ \\
Vitamin B12, ng/mL & $407.6(133.9)$ & $374.3(130.8)$ & 136.00 & 0.420 \\
Folate, pg/mL & $9.6(1.34)$ & $9.71(4.35)$ & 142.00 & 0.536 \\
\hline \multicolumn{2}{l}{ Data represent mean (SD). } & & & \\
$\quad$ Significant difference $(p<0.001)$. & & & \\
$\quad$ U, Mann Whitney U test. & & & & \\
\hline
\end{tabular}

partment. All subjects were $\geq 60$ years old, met the criteria of $A D$ at baseline according to ICD-10 (International Classification of Disease-10, 1992) [28] and had Mini Mental status Examination (MMSE) [29] score of 10-24. Exclusion criteria included patients having severe to advanced stage of $\mathrm{AD}$; patients receiving supplements of Vitamin B12 and Folic acid; patients with other forms of dementia such as fronto-temporal, vascular, and lewy body; patients receiving methotrexate and/or any anticonvulsants such as valproate, carbamazepine, phenytoin and phenobarbitone; patients with deranged kidney functions; patients who had taken acetylcholinesterase inhibitors, antipsychotics, antidepressants, and benzodiazepines in the last 4 weeks; patients with unreliable informant; patients with thyroid abnormalities, and patients on special diets.

Healthy controls were the healthy elderly recruited through word of mouth (carers for inpatients and outpatients of department of Geriatric Mental Health). Inclusion criteria were age $\geq 60$ years, MMSE score $>24$, absence of alcohol and substance abuse, absence of any neurological disease, and absence of any psychiatric disorder (after thorough assessment with Mini International Neuropsychiatric Interview [30]).

Cognitive and Behavioral Assessment

MMSE score was used to assess the severity of cognitive impairment. MMSE scale has 11 questions with a total score of 30 . The cutoff value to differentiate dementia patients from healthy elderly was changed according to the level of education of the elderlies. The cutoff values for different educational levels were: illiterate patient - less than 17 points, primary - less than 20 points and those with high school education - less than 24 points [29, 31-34]. Clinical staging of the AD patients was done with the Global Deterioration scale (GDS) [35]. In addition to cognitive functions, it also assesses the activity of daily living and abnormal behaviors of the patients. The GDS classifies the clinical stages of dementia into Seven Grades, which includes predementia stages (grades I-III) and the dementia stages (grades IV-VII). The Clinical Dementia Rating (CDR) scale was used to rate the performance in 6 domains: memory, orientation, judgment and problem solving, community affairs, home and hobbies, and personal care in patients through an interview with them/their caregiver [36].

BPSD were assessed using Neuropsychiatric Inventory (NPI) [37]. It was developed to assess the behavioral symptoms associated with dementia. NPI has been translated to different languages and used in many countries. NPI is also available in Hindi version, which was used for assessment in this study. The NPI has 12 subdomains for assessing the behavioral symptoms in dementia patients, namely, delusion, hallucinations, agitation/aggression, depression/dysphoria, anxiety, euphoria/elation, apathy/indifference, disinhibition, irritability/lability, aberrant motor behavior, sleep/night-time behavior, and appetite/eating changes. It also assesses the amount of caregiver distress caused by each behavior. The patients were assessed for BPSD on 12 sub-domains of NPI in the 4 weeks prior to the assessment [37].

\section{Biochemical Investigations}

The blood homocysteine, folate, and vitamin B12 concentration were measured in both $\mathrm{AD}$ patients and healthy controls. After the patients had fasted for a period of $12 \mathrm{~h}$ or longer, blood samples (3-5 $\mathrm{mL}$ of blood) were collected intravenously from their upper limb in the morning. Then blood samples were stored in Vacutainer tubes containing citrate; within not more than $30 \mathrm{~min}$, the samples were transferred to the department of biochemistry and analyzed in full autoanalyzer. The report of serum homocysteine level was given after 7 days, while Folate and Vitamin B12 reports were available within $24 \mathrm{~h}$. These tests were performed in the Laboratory of the Department of Biochemistry, KGMU, Lucknow.

\section{Statistical Analysis}

The data were analyzed using IBM SPSS statistic version 20 and Microsoft excel (Microsoft office professional plus 2013). The significant level of probability $p$ was set to less than 0.05 . The analyses included Mann Whitney U test and Spearman rank correlation coefficient when appropriate.

\section{Results}

\section{Demographic and Clinical Characteristics}

The baseline characteristics of the AD patients and healthy controls in the study are given in Table 1 . There were no differences in age, sex, and education level between the 2 groups. MMSE scores are significantly low in 
Table 2. Demographic, clinical, and biochemical characteristics of AD patients

\begin{tabular}{lc}
\hline & $\begin{array}{l}\text { AD patients, } \\
\text { mean } \\
(S D ; n=18)\end{array}$ \\
\hline Age, years & $74.5(8.54)$ \\
Gender, male:female & $10: 8$ \\
Education, years & $5.67(5.85)$ \\
Duration of dementia, years & $4.08(1.56)$ \\
MMSE & $14.44(4.15)$ \\
CDR & $1.61(0.5)$ \\
GDS & $4.94(0.99)$ \\
Homocysteine, $\mu$ mol/L & $11.59(1.51)$ \\
Vitamin B12, ng/mL & $374.3(130.8)$ \\
Folate, pg/mL & $9.71(4.35)$ \\
NPI Total & $22.17(6.50)$ \\
\end{tabular}

Table 3. Scores of NPI sub-domains in the BPSD group

\begin{tabular}{ll}
\hline NPI sub-domains & $\begin{array}{l}\text { NPI score, } \\
\text { mean } \\
(\mathrm{SD} ; n=18)\end{array}$ \\
\hline Delusion & $3.22(2.07)$ \\
Hallucination & $1.11(1.71)$ \\
Agitation/aggression & $3.11(2.08)$ \\
Depression/dysphoria & $3.00(2.30)$ \\
Anxiety & $1.56(2.12)$ \\
Euphoria/elation & $0.22(0.94)$ \\
Apathy/indifference & $0.33(1.03)$ \\
Disinhibition & $0.22(0.94)$ \\
Irritability/lability & $2.00(2.06)$ \\
Aberrant motor behavior & $2.78(2.07)$ \\
Sleep/night time behavior & $3.11(1.84)$ \\
Appetite/eating change & $1.50(1.50)$ \\
NPI Total & $22.17(6.50)$ \\
\hline
\end{tabular}

Table 4. Correlation of serum homocysteine levels with scores of the MMSE, CDR, and GDS and duration of dementia in AD patients

\begin{tabular}{lrrl}
\hline & \multicolumn{2}{l}{ AD patients $(n=18)$} & \\
\cline { 2 - 4 } & $\rho$ & $95 \%$ CI & $p$ value \\
\hline Duration of dementia & 0.198 & -0.389 to 0.750 & 0.430 \\
MMSE & 0.065 & -0.509 to 0.593 & 0.798 \\
CDR & -0.143 & -0.587 to 0.346 & 0.572 \\
GDS & 0.070 & -0.454 to 0.565 & 0.783 \\
\hline
\end{tabular}

$\rho$, Spearman correlation coefficient.
$\mathrm{AD}$ patients as compared to the scores of the control group (as expected; $p<0.001$ ).

Remaining clinical parameters of $\mathrm{AD}$ patients like CDR, GDS and total NPI scores are given in Table 2 and Table 3.

\section{Homocysteine, Folate, and Vitamin B12}

Concentrations in Participants

Mean homocysteine, vitamin B12, and folate concentrations in control group were $11.59 \mu \mathrm{mol} / \mathrm{L}$, $407.6 \mathrm{ng} / \mathrm{mL}$, and $9.6 \mathrm{pg} / \mathrm{mL}$, respectively, and in $\mathrm{AD}$ patients, they were $19.11 \mu \mathrm{mol} / \mathrm{L}, 374.3 \mathrm{ng} / \mathrm{mL}$, and $9.71 \mathrm{pg} / \mathrm{mL}$ respectively. As shown in Table 1, the homocysteine concentrations were significantly higher in $\mathrm{AD}$ patients as compared to those of the control group $(p<$ 0.01 ), while there was no significant difference in vitamin B12 and folate concentrations between the 2 groups.

\section{Correlation of Serum Homocysteine Levels with}

Duration of Dementia, MMSE, GDS, and CDR Scores

As shown in Table 4, serum homocysteine levels did not correlate significantly with the duration of dementia, MMSE, GDS, and CDR scores in AD patients.

\section{Correlation of Serum Homocysteine Levels with Scores of NPI}

As shown in Table 5, the serum homocysteine levels correlate significantly with total NPI scores in AD patients $(\rho=0.749, p<0.001$, Fig. 1). On further analyses with each NPI sub-domain, significant correlation of serum homocysteine levels was found with delusion, agitation/aggression, and depression/dysphoria (Table 5). However, no significant correlation was found between serum homocysteine levels and the other 9 sub-domains.

\section{Discussion}

\section{Relation of Homocysteine with MMSE Scores and} Duration of Dementia

This study did not find any significant negative correlation between MMSE scores and plasma tHcy levels in AD patients. MMSE score could reflect the degree of cognitive impairment. As MMSE scores decline, the degree of cognitive impairment increases. There are studies that have reported that increased homocysteine levels are correlated with decreased cognitive functions [26, 38, 39], but contradictory findings have been reported [25]. Results of the previous studies are inconsistent, but the overall results showed that high homocysteine levels are gen- 
Table 5. Correlation of serum homocysteine levels with scores of NPI

\begin{tabular}{|c|c|c|c|}
\hline \multirow[t]{2}{*}{ NPI sub-domains } & \multicolumn{3}{|c|}{ AD patients $(n=18)$} \\
\hline & $\rho$ & $95 \% \mathrm{CI}$ & $p$ value \\
\hline Delusion & 0.602 & 0.252 to 0.838 & $0.008^{*}$ \\
\hline Hallucination & 0.151 & -0.413 to 0.677 & 0.549 \\
\hline Agitation/aggression & 0.610 & 0.265 to 0.810 & $0.007^{*}$ \\
\hline Depression/dysphoria & 0.586 & 0.155 to 0.858 & $0.011^{*}$ \\
\hline Anxiety & 0.203 & -0.279 to 0.675 & 0.418 \\
\hline Euphoria/elation & 0.257 & 0.117 to 0.564 & 0.303 \\
\hline Apathy/indifference & -0.155 & -0.549 to 0.211 & 0.539 \\
\hline Disinhibition & 0.164 & -0.024 to 0.450 & 0.517 \\
\hline Irritability/lability & 0.237 & -0.248 to 0.660 & 0.343 \\
\hline Aberrant motor behavior & -0.296 & -0.671 to 0.199 & 0.233 \\
\hline Sleep/night time behavior & -0.218 & -0.565 to 0.213 & 0.385 \\
\hline Appetite/eating change & 0.369 & -0.079 to 0.705 & 0.132 \\
\hline NPI total score & 0.749 & 0.396 to 0.920 & $0.000^{\dagger}$ \\
\hline
\end{tabular}

* Significant difference $(p<0.05)$.

† Significant difference $(p<0.001)$.

$\rho$, Spearman correlation coefficient.

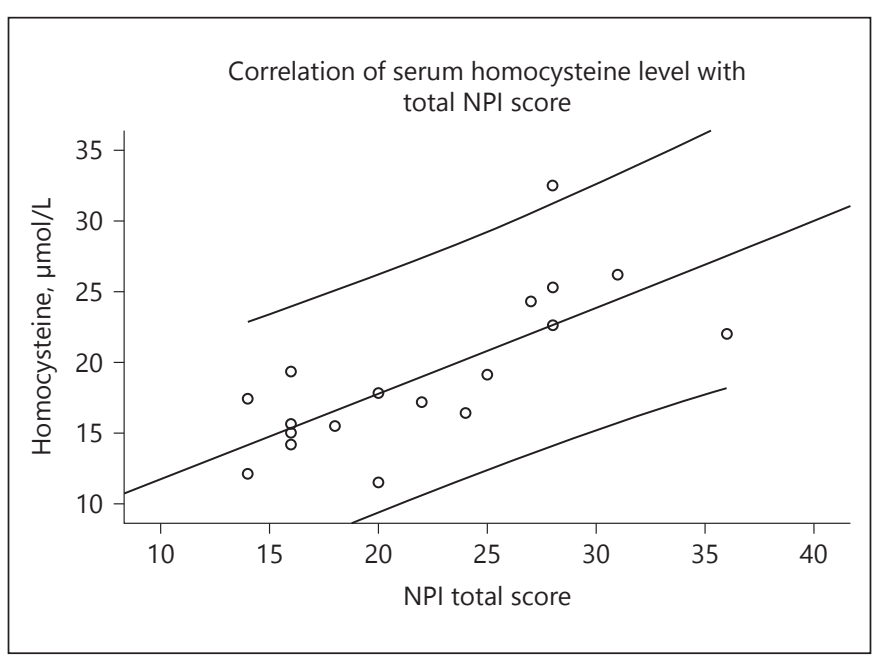

Fig. 1. Scatter diagram to show the correlation of tHcy level with total NPI score in AD patients. NPI, neuropsychiatric inventory. $\rho=0.749$ (Spearman Rank Correlation). $p<0.001$.

erally correlated with decreased cognitive functions. However, the results of the present study were contradictory but are in accordance with findings of Tabet et al. [25]. Reason for such findings may be the smaller sample size, which was also present in Tabet's study. Those studies that have shown negative correlation had relatively a large number of $\mathrm{AD}$ patients in their recruited sample
$[26,39]$. Findings of this study implicate that increased plasma tHcy level is not associated with cognitive decline in $\mathrm{AD}$ patients.

This study also did not find any correlation between the plasma tHcy level and duration of dementia in $\mathrm{AD}$ patients. It showed that homocysteine did not increase gradually with progression of AD. Nilsson et al. [40] had found that plasma homocysteine concentration relates to the severity but not to the duration of $\mathrm{AD}$, which is consistent with our findings. AD has complex etiology in which multiple factors play together. Homocysteine may be one of such factors and not the main or primary one. However, it can be possible that homocysteine, by various mechanisms, contributes to the occurrence of $\mathrm{AD}$ or aggravates the pathophysiological damage, which is responsible for the progressive cognitive decline in $\mathrm{AD}$.

\section{Relation between Serum Homocysteine and BPSD}

This study was aimed to investigate the correlation of serum homocysteine levels with BPSD in patients of AD. The correlation of homocysteine with cognitive functions was studied extensively in the past, but the relationship between BPSD and homocysteine in dementia is not given enough attention till date. The result of this study showed that the serum homocysteine level is significantly correlated with the total NPI score in AD patients. Apart from this, the delusion; agitation/aggression, and depression/dysphoria sub-domains of NPI also showed significant correlation with homocysteine. Studies that have found association between homocysteine and BPSD are very few $[26,27]$. Negative findings were reported by one study [25]. The results of this study are partially in accordance with the results of the study by Kim and Lee [27], which found significant correlation of plasma tHcy level with the total NPI score as well as with following NPI sub-domains: delusion, agitation/ aggression, depression/dysphoria, elation/euphoria, apathy/indifference, and disinhibition. It is difficult to explain these differences, but the smaller sample size of our study (18 as compared to $77 \mathrm{AD}$ patients of the study by Kim and Lee [27]) could be one possible reason for these differences. Study results implicate that high plasma tHcy level is associated with BPSD in AD patients, particularly delusion, agitation/aggression, and depression/ dysphoria.

Limited research has been done on correlation between homocysteine and thought disorders like delusion. Monji et al. [19] reported that higher homocysteine levels in a patient of epilepsy was associated with interictal psy- 
chosis, while Spiro et al. [41] reported that some of the patients with schizophrenia had homocystinuria, which may be because of the defect in methionine metabolism. Later on, one study had showed that $45 \%$ of the patients of schizophrenia had higher homocysteine concentration [42]. However, Virgos et al. [43] reported contradictory findings and showed that the blood homocysteine concentration was not significantly different between schizophrenia patients and normal subjects. According to previous studies, though results are not consistent, it can be assumed that hyperhomocysteinemia may be correlated to schizophrenia like psychosis to some extent. Recently, Kim and Lee [27] found a positive correlation between the plasma tHcy level and delusion and agitation/aggression in $\mathrm{AD}$ patients. Various mechanisms have been suggested to explain the correlation between hyperhomocysteinemia and schizophrenia like psychosis. Possible theories are as follows: (1) homocysteine acts as an agonist at the glutamate site and as a partial antagonist of the glycine co-agonist site of N-Methyl D-Aspartic acid receptors, which results into excessive intracellular calcium influx and neuronal death [44, 45], (2) increased level of homocysteine creates a state of hypomethylation $[46,47]$, which causes deoxyribonucleic acid (DNA) damage and apoptosis [48-50]. In the present study, the scores of delusion and agitation/aggression sub-domain of the NPI were increased in the AD patients as the homocysteine concentration increased, which suggests that the psychotic symptoms in AD were caused by a similar mechanism to that of schizophrenia.

Studies on correlation of depression and homocysteine in dementia patients are very few. Two previous studies have reported that the presence of major depressive disorders in patients with AD was correlated with hyperhomocysteinemia $[27,51]$. Several studies have tried to identify the relationship between depression and homocysteine in elderly patients, but the results were not consistent [52-55]. In the present study, the homocysteine levels and the NPI scores in the depression/dysphoria sub-domain were significantly correlated, a finding similar to the results of the previous studies $[27,51]$. This relationship of homocysteine and depression cannot be attributed to a particular mechanism, but several hypotheses have been suggested to explain this correlation. Vascular depression hypothesis can be one possible explanation. The presence of depression, vascular disease, and vascular risk factors together, along with the association of ischemic lesions to specific behavioral symptoms supports "Vascular depression hypothesis." The central mechanism underlying the vascular depression hypoth- esis can be the disruption of prefrontal white matter pathways or their modulating pathways by single lesions or by an accumulation of lesions exceeding a threshold [56]. When homocysteine is accumulated, it inhibits the production of prostacyclin and leads to the accumulation of low-density lipoprotein, which damages the blood vessel wall $[16,17]$. According to vascular depression hypothesis, it is assumed that the high level of homocysteine causes the damage and chronic inflammatory responses in vascular endothelial cells, which exacerbates AD and results into vascular depression because of the vascular pathology. It is established that the chronic inflammation is one of the key mechanisms of $\mathrm{AD}$ [57-59].

\section{Study Limitations}

This study has several limitations. First, the number of $\mathrm{AD}$ patients was not large. Second, the research was conducted in a tertiary care referral hospital situated in an urban area, the findings cannot be generalized. Third, the inferences drawn from this study are limited by its crosssectional design.

\section{Summary and Conclusion}

The study found associations between serum homocysteine levels and BPSD, which raises the possibility of the etiological role of homocysteine in pathophysiology of BPSD in AD. However, the pathophysiological mechanisms underlying these associations need to be elucidated further because correlation does not necessarily imply a causative relation. This was a cross-sectional study, findings of which cannot be generalized, and should be confirmed through prospective longitudinal studies on a larger group of the patients with dementia. The relationship of low vitamin B12, folate, or high homocysteine levels with BPSD should be studied in depth. In future, we may have better understanding of the relationship between BPSD and folate, vitamin B12 and homocysteine though large prospective, longitudinal studies with consistent results, which will help us to determine whether or not to give vitamin B12 and folate as therapeutic drugs for treatment of BPSD in dementia.

Finally, the authors concluded from the study results that the serum homocysteine level in Indian $\mathrm{AD}$ patients showed significant correlation with BPSD in AD patients. The BPSD particularly delusion, agitation/aggression, and depression were correlated significantly with the homocysteine level. One must go for investigations of vitamin B12, folate and homocysteine in a patient of $\mathrm{AD}$ patient with BPSD and give a therapeutic trial of folate and vitamin B12. 


\section{Acknowledgments}

My special thanks to Dr. Shrikant Srivastava, Dr. Shailendra Mohan Tripathi, Dr. Bhupendra Singh, Dr. Rakesh Kumar Tripathi, Dr. Nisha Mani Pandey, Dr. Priti Singh (Faculty members of Department of Geriatric Mental Health) and all senior residents for all the help they have rendered to me during this study.

\section{Ethics Statement}

The study was approved by the Institutional Ethics Committee of King George's Medical University, Lucknow, India. Written informed consent was obtained from all study participants/their caregivers. This study was performed in accordance with Declaration of Helsinki (current version: Fortaleza, Brazil, October 2013).

\section{Disclosure Statement}

The manuscript complies with the ICMJE statement. The authors declare that they have no conflicts of interest to disclose.

\section{Funding Source}

None.

\section{Author Contribution}

R.M.S. has contributed to concepts, design, definition of intellectual content, Literature search, Clinical studies, Experimental studies, Data acquisition, Data analysis, Manuscript preparation, Statistical analysis, Manuscript editing, Manuscript review, and guarantor. S.C.T. has contributed to concepts, design, definition of intellectual content, Literature search, Clinical studies, Data analysis, Manuscript preparation, Statistical analysis, Manuscript editing, Manuscript review, and guarantor. A.A.M. has contributed to concepts, design, definition of intellectual content, Literature search, Statistical analysis, Manuscript editing, Manuscript review, and guarantor. Dr. Neera Kohli has contributed to concepts, design, definition of intellectual content, Literature search, Statistical analysis, Manuscript editing, Manuscript review, and guarantor.

\section{References}

$>_{1}$ Fuentealba RA, Farias G, Scheu J, Bronfman M, Marzolo MP, Inestrosa NC: Signal transduction during amyloid-beta-peptide neurotoxicity: role in Alzheimer disease. Brain Res Brain Res Rev 2004;47:275-289.

$\checkmark 2$ Tiwari SC, Soni RM: Alzheimer's disease pathology and oxidative stress: possible therapeutic options. J Alzheimer's Dis Park 2014;4: 1-10.

3 Kales HC, Gitlin LN, Lyketsos CG: Assessment and management of behavioral and psychological symptoms of dementia. BMJ 2015 Jan;350:h369.

-4 Seitz DP, Adunuri N, Gill SS, Gruneir A, Herrmann N, Rochon P: Antidepressants for agitation and psychosis in dementia. Cochrane database Syst Rev 2011;2:CD008191.

5 Tariot PN, Mack JL, Patterson MB, Edland SD, Weiner MF, Fillenbaum G, et al: The behavior rating scale for dementia of the consortium to establish a registry for Alzheimer's disease. The behavioral pathology committee of the consortium to establish a registry for Alzheimer's disease. Am J Psychiatry 1995; 152:1349-1357.

-6 Fernández-Martínez M, Castro J, Molano A, Zarranz JJ, Rodrigo RM, Ortega R: Prevalence of neuropsychiatric symptoms in Alzheimer's disease and vascular dementia. Curr Alzheimer Res 2008;5:61-69.

$\checkmark 7$ Ferri CP, Ames D, Prince M: Behavioral and psychological symptoms of dementia in developing countries. Int Psychogeriatr 2004; 16:441-459.

8 Steinberg M, Sheppard JM, Tschanz JT, Norton MC, Steffens DC, Breitner JC, et al: The incidence of mental and behavioral disturbances in dementia: the cache county study. J Neuropsychiatry Clin Neurosci 2003;15:340345.

-9 Quadri P, Fragiacomo C, Pezzati R, Zanda E, Forloni G, Tettamanti M, et al: Homocysteine, folate, and vitamin B-12 in mild cognitive impairment, Alzheimer disease, and vascular dementia. Am J Clin Nutr 2004;80:114-122.

10 Stuerenburg HJ, Mueller-Thomsen T, Methner A: Vitamin B 12 plasma concentrations in Alzheimer disease. Neuro Endocrinol Lett 2004;25:176-177.

11 Bottiglieri T: Folate, vitamin B12, and neuropsychiatric disorders. Nutr Rev 1996;54:382390.

12 Engelborghs S, Vloeberghs E, Maertens K, Mariën P, Somers N, Symons A, et al: Correlations between cognitive, behavioural and psychological findings and levels of vitamin B12 and folate in patients with dementia. Int J Geriatr Psychiatry 2004;19:365-370.

13 Whyte EM, Mulsant BH, Butters MA, Qayyum M, Towers A, Sweet RA, et al: Cognitive and behavioral correlates of low vitamin B12 levels in elderly patients with progressive dementia. Am J Geriatr Psychiatry 2002;10:321327.

14 Vogel T, Dali-Youcef N, Kaltenbach G, Andrès E: Homocysteine, vitamin B12, folate and cognitive functions: a systematic and critical review of the literature. Int J Clin Pract 2009;63:1061-1067.

15 Nilsson K, Gustafson L, Hultberg B: Plasma homocysteine is a sensitive marker for tissue deficiency of both cobalamines and folates in a psychogeriatric population. Dement Geriatr Cogn Disord 1999;10:476-482.

16 Fácila L, Nuñez JE, G VB, Sanchis J, Bodi V, Chorro FJ, et al: Early determination of homocysteine levels in acute coronary syndromes, is it an independent prognostic factor? Int J Cardiol 2005;100:275-279.

17 Virtanen JK, Voutilainen S, Happonen P, Alfthan G, Kaikkonen J, Mursu J, et al: Serum homocysteine, folate and risk of stroke: kuopio ischaemic heart disease risk factor (KIHD) Study. Eur J Cardiovasc Prev Rehabil 2005;12: 369-375.

18 Reif A, Pfuhlmann B, Lesch KP. Homocysteinemia as well as methylenetetrahydrofolate reductase polymorphism are associated with affective psychoses. Prog Neuropsychopharmacol Biol Psychiatry 2005;29: 1162-1168.

19 Monji A, Yanagimoto K, Maekawa T, Sumida Y, Yamazaki K, Kojima K: Plasma folate and homocysteine levels may be related to interictal "schizophrenia-like" psychosis in patients with epilepsy. J Clin Psychopharmacol 2005; 25:3-5.

20 Dittmann S, Seemüller F, Grunze HC, Schwarz MJ, Zach J, Fast K, et al: The impact of homocysteine levels on cognition in euthymic bipolar patients: a cross-sectional study. J Clin Psychiatry 2008;69:899906.

21 Osher Y, Bersudsky Y, Silver H, Sela BA Belmaker RH: Neuropsychological correlates of homocysteine levels in euthymic bipolar patients. J Affect Disord 2008;105: 229-233. 
22 Levine J, Stahl Z, Sela BA, Ruderman V, Shumaico O, Babushkin I, et al: Homocysteinereducing strategies improve symptoms in chronic schizophrenic patients with hyperhomocysteinemia. Biol Psychiatry 2006;60:265269.

-23 Sachdev PS, Parslow RA, Lux O, Salonikas C, Wen W, Naidoo D, et al: Relationship of homocysteine, folic acid and vitamin B12 with depression in a middle-aged community sample. Psychol Med 2005;35:529-538.

24 Almeida OP, McCaul K, Hankey GJ, Norman P, Jamrozik K, Flicker L: Homocysteine and depression in later life. Arch Gen Psychiatry 2008;65:1286-1294.

25 Tabet N, Rafi H, Weaving G, Lyons B, Iversen SA: Behavioural and psychological symptoms of Alzheimer type dementia are not correlated with plasma homocysteine concentration. Dement Geriatr Cogn Disord 2006;22:432438.

26 Zheng Z, Wang J, Yi L, Yu H, Kong L, Cui W, et al: Correlation between behavioural and psychological symptoms of Alzheimer type dementia and plasma homocysteine concentration. Biomed Res Int 2014;2014:383494.

-27 Kim H, Lee KJ: Serum homocysteine levels are correlated with behavioral and psychological symptoms of Alzheimer's disease. Neuropsychiatr Dis Treat 2014;10:1887-1896.

28 World Health Organization: The ICD-10 classification of mental and behavioural disorders. Int Classif 1992;10:1-267.

-29 Folstein MF, Folstein SE, McHugh PR: "Minimental state". A practical method for grading the cognitive state of patients for the clinician. J Psychiatr Res 1975;12:189-198.

- 30 Solias A, Skapinakis P, Degleris N, Pantoleon M, Katirtzoglou E, Politis A: [Mini Mental State Examination (MMSE): determination of cutoff scores according to age and educational level]. Psychiatr 2014;25:245-256.

- 31 O’Bryant SE, Humphreys JD, Smith GE, Ivnik RJ, Graff-Radford NR, Petersen RC, et al: Detecting dementia with the mini-mental state examination in highly educated individuals. Arch Neurol 2008;65:963-967.

32 Crum RM, Anthony JC, Bassett SS, Folstein MF: Population-based norms for the MiniMental State Examination by age and educational level. JAMA 1993;269:2386-2391.

-33 Bravo G, Hébert R: Age- and education-specific reference values for the mini-mental and modified mini-mental state examinations derived from a non-demented elderly population. Int J Geriatr Psychiatry 1997;12:10081018.

- 34 Sheehan DV, Lecrubier Y, Sheehan KH, Amorim P, Janavs J, Weiller E, et al: The Mini-International Neuropsychiatric Interview (M.I.N.I.): the development and validation of a structured diagnostic psychiatric interview for DSM-IV and ICD-10. J Clin Psychiatry 1998;59(suppl 20):22-33.
35 Reisberg B, Ferris SH, de Leon MJ, Crook T: The global deterioration scale for assessment of primary degenerative dementia. Am J Psychiatry 1982;139:1136-1139.

36 Morris JC, Berg L, Cohen LA, Rubin EH, Deuel R, Wittenborn R, Coats M, Leon S, Norton J: Treating Alzheimer's and other dementias: Clinical Application of Recent Research Advances; in Bergener M, Finkel SI (eds): New York, Springer Publishing, 1995, pp 338-346.

37 Cummings JL, McPherson S: Neuropsychiatric assessment of Alzheimer's disease and related dementias. Aging (Milano) 2001;13: 240-246.

38 McCaddon A, Hudson P, Davies G, Hughes A, Williams JH, Wilkinson C: Homocysteine and cognitive decline in healthy elderly. Dement Geriatr Cogn Disord 2001;12:309-313.

39 Oulhaj A, Refsum H, Beaumont H, Williams J, King E, Jacoby R, et al: Homocysteine as a predictor of cognitive decline in Alzheimer's disease. Int J Geriatr Psychiatry 2010;25:8290.

40 Nilsson K, Gustafson L, Hultberg B: Plasma homocysteine concentration relates to the severity but not to the duration of Alzheimer's disease. Int J Geriatr Psychiatry 2004;19:666672.

41 Spiro HR, Schimke RN, Welch JP: Schizophrenia in a patient with a defect in methionine metabolism. J Nerv Ment Dis 1965;141: 285-290.

42 Regland B, Johansson BV, Grenfeldt B, Hjelmgren LT, Medhus M: Homocysteinemia is a common feature of schizophrenia. J Neural Transm Gen Sect 1995;100:165-169.

43 Virgos C, Martorell L, Simó JM, Valero J, Figuera L, Joven J, et al: Plasma homocysteine and the methylenetetrahydrofolate reductase C677T gene variant: lack of association with schizophrenia. Neuroreport 1999;10:20352038.

44 Lehmann J, Tsai C, Wood PL: Homocysteic acid as a putative excitatory amino acid neurotransmitter: I. Postsynaptic characteristics at N-methyl-D-aspartate-type receptors on striatal cholinergic interneurons. J Neurochem 1988;51:1765-1770.

-45 Lipton SA, Kim WK, Choi YB, Kumar S, D'Emilia DM, Rayudu PV, et al: Neurotoxicity associated with dual actions of homocysteine at the $\mathrm{N}$-methyl-D-aspartate receptor. Proc Natl Acad Sci U S A 1997;94:5923-5928.

- 46 Weir DG, Scott JM: Brain function in the elderly: role of vitamin B12 and folate. Br Med Bull 1999;55:669-682.

47 Bottiglieri T, Godfrey P, Flynn T, Carney MW, Toone BK, Reynolds EH: Cerebrospinal fluid S-adenosylmethionine in depression and dementia: effects of treatment with parenteral and oral S-adenosylmethionine. J Neurol Neurosurg Psychiatry 1990;53:10961098.
48 Huang RF, Huang SM, Lin BS, Wei JS, Liu TZ: Homocysteine thiolactone induces apoptotic DNA damage mediated by increased intracellular hydrogen peroxide and caspase 3 activation in HL-60 cells. Life Sci 2001;68:27992811.

49 Kim HJ, Cho HK, Kwon YH: Synergistic induction of ER stress by homocysteine and beta-amyloid in SH-SY5Y cells. J Nutr Biochem 2008;19:754-761.

50 Kruman II, Culmsee C, Chan SL, Kruman Y, Guo Z, Penix L, et al: Homocysteine elicits a DNA damage response in neurons that promotes apoptosis and hypersensitivity to excitotoxicity. J Neurosci 2000;20:69206926.

51 Chen CS, Chou MC, Yeh YC, Yang YH, Lai CL, Yen CF, et al. Plasma homocysteine levels and major depressive disorders in Alzheimer disease. Am J Geriatr Psychiatry 2010;18: 1045-1048.

52 Bottiglieri T, Laundy M, Crellin R, Toone BK, Carney MW, Reynolds EH: Homocysteine, folate, methylation, and monoamine metabolism in depression. J Neurol Neurosurg Psychiatry 2000;69:228-232.

53 Nabi H, Bochud M, Glaus J, Lasserre AM, Waeber G, Vollenweider P, et al: Association of serum homocysteine with major depressive disorder: results from a large populationbased study. Psychoneuroendocrinology 2013;38:2309-2318.

54 Naismith S, Hickie I, Ward PB, Turner K, Scott E, Little C, et al: Caudate nucleus volumes and genetic determinants of homocysteine metabolism in the prediction of psychomotor speed in older persons with depression. Am J Psychiatry 2002;159:2096-2098.

55 Tiemeier H, van Tuijl HR, Hofman A, Meijer J, Kiliaan AJ, Breteler MM: Vitamin B12, folate, and homocysteine in depression: the Rotterdam Study. Am J Psychiatry 2002;159: 2099-2101.

56 Alexopoulos GS, Meyers BS, Young RC, Campbell S, Silbersweig D, Charlson M: 'Vascular depression' hypothesis. Arch Gen Psychiatry 1997;54:915-922.

57 Blasko I, Stampfer-Kountchev M, Robatscher P, Veerhuis R, Eikelenboom P, Grubeck-Loebenstein B: How chronic inflammation can affect the brain and support the development of Alzheimer's disease in old age: the role of microglia and astrocytes. Aging Cell 2004;3: 169-176.

58 Blasko I, Grubeck-Loebenstein B: Role of the immune system in the pathogenesis, prevention and treatment of Alzheimer's disease. Drugs Aging 2003;20:101-113.

59 Karabag T, Kaya A, Temizhan A, Koç F, Yavuz S, Cam S: The influence of homocysteine levels on endothelial function and their relation with microvascular complications in T2DM patients without macrovascular disease. Acta Diabetol 2007;44:69-75 